\title{
The Perceived Health Effects of E-cigarette Use Among Adult Smokers
}

\section{Joey Cheng', Dale Chen ${ }^{2}$}

1 Lead Author, School of Health Sciences, British Columbia Institute of Technology, Burnaby, BC

2 Supervisor, School of Health Sciences, British Columbia Institute of Technology, Burnaby, BC

\begin{abstract}
Background: Vaping and e-cigarettes have been an epidemic among youths in recent years. In addition, as of April 2020, there has been hundreds of vaping related illnesses causing fatalities. As such there has been increased coverage by media and the government in regard to reporting vapingrelated dangers and implementing regulatory changes such as bans. These actions could deter the target population from engaging in vaping - tobacco users. Research has shown that e-cigarettes are significantly less toxic relative to tobacco and that it could be more effective as a cessation treatment relative to nicotine gums or patches. This study surveyed current perceptions of Canadians with regards to vaping in order to determine if certain groups (i.e. varying ages, smoking status) hold different opinions in terms of harm, health benefits, and support for stricter e-cigarette regulations.
\end{abstract}

Methods: Self-administered online surveys created on Survey Monkey were distributed to Canadians via online platforms Reddit and Facebook. The survey assessed opinions and perceptions of Canadians through multiple choice questions and were collected over a three week period.

Results: This study received 157 respondents the majority of which were under $35(73.08 \%)$ and from British Columbia (65.38\%). Thirteen chi-square tests were performed comparing group variables (age, smoking status, and awareness of vaping related news) to perception variables (perceived harm, health benefits, safety). There was no association found between age and the tested perception variables. Several associations were found where e-cigarette users viewed ecigarettes more favourably relative to tobacco users and non-users based on chi-square results. Chisquare associations between media awareness and harm perceptions could not be established due to a small sample size $(\mathrm{n}<30)$.

Conclusion: The results indicated that there are associations with e-cigarette perceptions and a person's smoking status. This may be an indication that there is possible misinformation between groups when it comes to evaluating objective health effects of e-cigarettes. Non-users and a percentage of tobacco users seem to overstate the health consequences and tobacco smokers who transitioned are understating the health effects.

Keywords: E-cigarettes, vaping, perceptions, beliefs, harm

\section{Introduction}

Tobacco smoke has been identified as a major health issue, causing problems such as lung cancer, cardiovascular and respiratory diseases (Health Canada,
2016). The risk isn't just limited to the users. People exposed second-hand smoke are also at an increased risk for the same health problems as smokers. 
Vaping or e-cigarettes are currently being used by smokers as a cessation aid to help quit smoking (Reid et al., 2019). There is a growing body of evidence showing that vaping is a safer alternative to smoking which can help improve the health of tobacco smokers. However, several countries such as India and the United States are looking to ban these products due to their impact on youths (BBC News, 2019; Hammond et al., 2019; Reuters, 2019). Youth vaping rates are currently increasing which can cause addiction to e-cigarettes and be a gateway for other drugs such as tobacco cigarettes. In addition, there has been hundreds of cases of vaping related illnesses where the specific cause is unknown (CDC, 2020).

This study has found that a significant number of Canadians, non-users and tobacco users, are overestimating the health deficits involving e-cigarette use . In the same vein, e-cigarette users are understating the health effects. This shows that there is a misunderstanding of the true health effects that vaping entails and needs to be addressed

\section{Literature Review}

Smoking prevalence has decreased at a steady rate over the past five decades, from approximately $37 \%$ of the country being smokers in 1965 to $15.1 \%$ in 2017 (Reid et al., 2019). Two-thirds of smokers who attempted to quit used some form of cessation assistance, the most common of which were e-cigarettes (32.4\%), nicotine replacement therapy (30.8\%), and medications (14.7\%) (Reid et al., 2019).

The vaping trends of youths ages from 16-19 years old in Canada, US, and Europe has increased in Canada and the US, but remained stable in Europe (Hammond et al., 2019). The lack of increase of prevalence in Europe is speculated to be due to their mandatory limits on nicotine concentrations for eliquids and greater restrictions on marketing. In comparison, Canada had an unregulated market for vaping in terms of advertising and recently made regulatory changes to e-cigarettes by implementing new taxes, health warnings, and plain packaging requirements (Government of Canada, 2020).

Prior to this, e-cigarette retailers are allowed to market flavouring and have appealing packaging including ads which display images of fruits (CBC News, 2019). Researchers and health officials are concerned with the continual growth of e-cigarette brands such as JUUL, which could foster a new generation addicted to vaping (Hammond et al., 2019). A need for ad restrictions is urgent due to the growing number of young people who have the potential to grow addicted (Hammond et al., 2019). It is possible that, when ad restrictions are implemented, youth vaping rates will stabilize as seen in Europe and we can reframe advertisements of e-cigarettes as a product designed for smoking cessation. 
Public Health England determined that ecigarettes are around $95 \%$ safer than tobacco smokes and can help users to quit (Mcneill et al., 2015). This conclusion was reached by a systematic review of over 150 published papers in addition to their own surveys. This review also assessed behavioural evidence and determined that there has been a shift towards the perception that E-cigarettes as being as harmful as cigarettes. One of the reasons for this change in perception is from misinterpretations of research findings and media headlines asserting the e-cigarettes are dangerous (Mcneill et al., 2015).

The exposure to toxins from vaping is exponentially lower compared to smoking (Farsalinos \& Polosa, 2014). A systemic review of 41 studies profiled the risk of ecigarettes based on and found that a majority of $>4000$ chemicals found in tobacco smoke were absent from vapes - due to the lack of combustion byproducts (Farsalinos \& Polosa, 2014).. Ecigarettes also have lower quantities of chemical exposure compared to cigarettes. In one of the evaluated chemicals, there were approximately 13 nanograms $/ \mathrm{ml}$ of nitrosamines in vapes and 3365-6260 nanograms of nitrosamines per cigarette (depending on brand) (Farsalinos \& Polosa, 2014).

There are currently no accurate comparisons for cigarettes and e-liquids available (i.e. we cannot say one cigarette is equal to $0.1 \mathrm{ml}$ of e-liquid). This is due to differences in user intake (puffs), the type of vaporizing device, and concentrations of chemicals between liquids. However, an online retailer's information blog states that a smoker that smokes one pack of cigarettes will use approximately 3-4 $\mathrm{ml}$ of e-liquid when using a small E-cigarette or as high as 7-9 $\mathrm{ml}$ when using sub-ohm kits (Canada Vaping Info, 2019). Even though this comparison is inaccurate, it is negligible due to the drastic difference in nitrosamine levels. An e-cigarette user would never use enough e-liquid to reach the same quantity of nitrosamines found in cigarettes. Based on current evidence, e-cigerettes are less harmful compared to tobacco cigarettes.

Although vapes have less chemical exposure compared to cigarettes, there are certain chemicals that can be found in certain e-liquids that can affect the human body not found in tobacco cigarettes. Behar et al. (2014) identified that cinnamon flavoured e-liquids caused respiratory irritation in some users. The surveillance of vapes is warranted due to unknown reactions when the chemicals enter the body and the variety of flavouring agents and chemicals that are available. However, many flavours are not causing irritation in smokers and there is not enough support to conclude that ecigarettes are as harmful as smoking (Farsalinos \& Polosa, 2014; Mcneill et al., 2015). 
The increase in the proportion of adults who perceived e-cigarettes to be equally or more harmful than cigarettes found by Public Health England's review may reflect consumers uncertainty about ecigarette's long-term health effects (Mcneill et al., 2015). This increase may be due to frequent media reports that link e-cigarettes and e-liquid to exposure to toxicants, serious injuries, and other health-related problems (Mcneill et al., 2015; Shin et al., 2017). Furthermore there may be confusion between relative risk and absolute risk of e-cigarettes in risk communication and media reports where absolute harm is overstated and relative harm is downplayed (FDA, 2019; Mcneill et al., 2015).

A lack of accurate and consistent risk communications to the public may contribute to the confusion about the health risks of e-cigarettes and education regarding these products need to be addressed (Mcneill et al., 2015). Another study assessed attitudes of young smokers in China and found that over half of the participants understated the effects of cigarettes (W. Wang, He, Feng, \& Cai, 2019; X. Wang, Zhang, Xu, \& Gao, 2019). In addition, some health professionals are also found to have inaccurate information regarding vaping effects (Shin et al., 2017; Zgliczyński et al., 2019). There is conflicting information regarding the true health effects of vaping and they should be addressed before proceeding to extreme measures such as banning all vaping products

\section{Methods}

A self administered survey was conducted online through SurveyMonkey with the license provided by BCIT. The survey was distributed through the online platforms Facebook and Reddit with IP tracking disabled to ensure anonymity (Surveymonkey, 2020). On Facebook, the survey was distributed through peers, colleagues and the Abbotsford discussion board page. It was also posted on the following subreddits: canadian_ecigarette, vaping, sample size, assistance, electronic_cigarette, and BCIT. These groups were chosen based on the moderator's willingness to host the survey and to find specific user samples (i.e. e-cigarette users). Microsoft Excel and NCSS statistical software was used to analyze and compile the data collected. In order to collect enough samples for older populations the survey was disseminated through e-messages to older peers and colleagues, requesting them to disseminate it to their older in-groups. Included participants were Canadians of legal smoking age in their respective province, which is over 18 or 19 (Munroe, 2019). Questions were asked regarding demographics and if they answered that they are under 18 or 19 and/or reside outside of Canada they were redirected to the end of the survey. Ethics approval was required from the BCIT 
Research Ethics Board before

administering the survey, which is a

process that evaluates and identifies ways

to minimizes possible risks to participants

(BCIT, 2020). A consent form was

provided to participants to ensure that

they understood their rights, what their

data was used for, and the purpose of the research.

\section{Results}

\section{Descriptive Data}

This survey received 157 respondents. The respondents were primarily between the ages of $18-24(41.67 \%, \mathrm{~N}=49)$ and $25-35(31.41 \%, \mathrm{~N}=65)$ both totalling to $73.08 \%(\mathrm{~N}=114)$. Most participants were from British Columbia (65.38\%, $\mathrm{N}=102)$. The Gender breakdown is as follows: Male (72.39\%, N=97), Female (26.12\%. $\mathrm{N}=35)$, and Other (1.49\% $\mathrm{N}=2)$.

\section{FiguRE 1. SURVEY RESPONDENT'S AGE GROUPS}

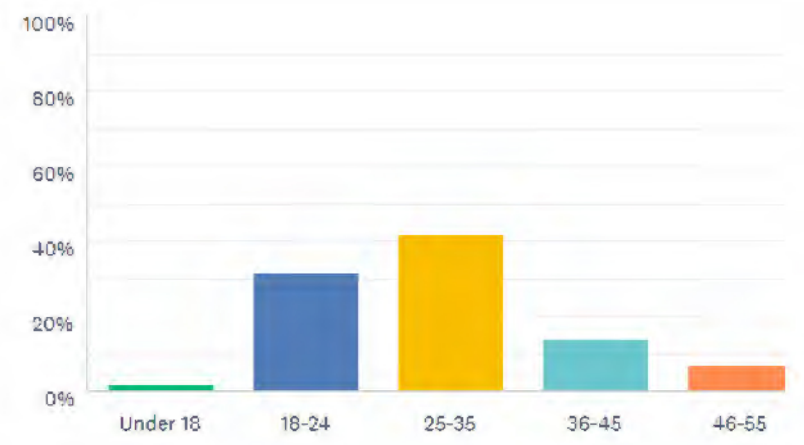

There were a mix of non-users $(36.30 \%$, $\mathrm{N}=49)$, smokers $(22.22 \%, \mathrm{~N}=30)$, ecigarette users $(16.30 \%, \mathrm{~N}=22)$ and users of both $(25.19 \%, \mathrm{~N}=34)$.
FIGURE 2. SURVEY RESPONDENT'S SMOKING AND VAPING STATUS

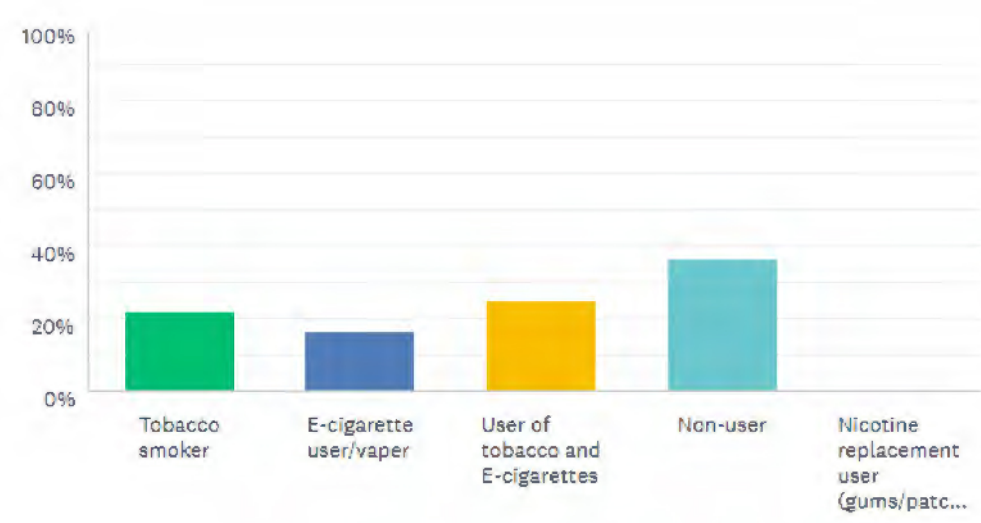

The majority of respondents did not agree with bans or stricter regulations that are harsher than tobacco cigarettes $(72.31 \%$, $\mathrm{N}=94$ ). In contrast, they also did not believe that e-cigarettes were harmless (76.52\%, N=101) nor that they were just as harmful as tobacco cigarettes $(59.23 \%$, $\mathrm{N}=77$ ). The majority also disagreed that it was okay to use e-cigarettes around nonsmoking peers $(55.73 \%, \mathrm{~N}=73)$, and that it was not okay around children $(78.03 \%$, $\mathrm{N}=103$ ).

Figure 3. Respondent PerCeptions of E-CIGARETTES BEING AS HARMFUL AS TOBACCO CigaretTES

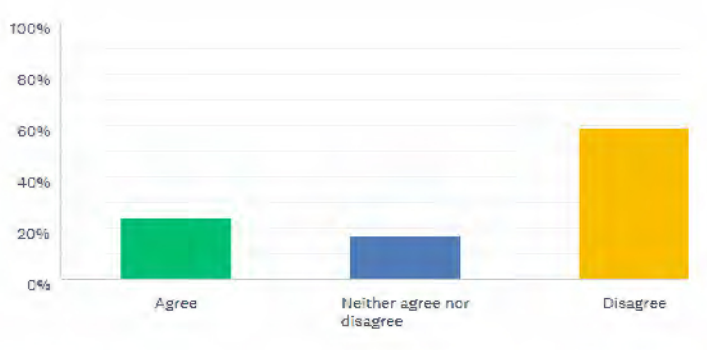


Figure 4. RESPONDENT PERCEPTIONS OF E-CIGARETTES BEING HARMLESS

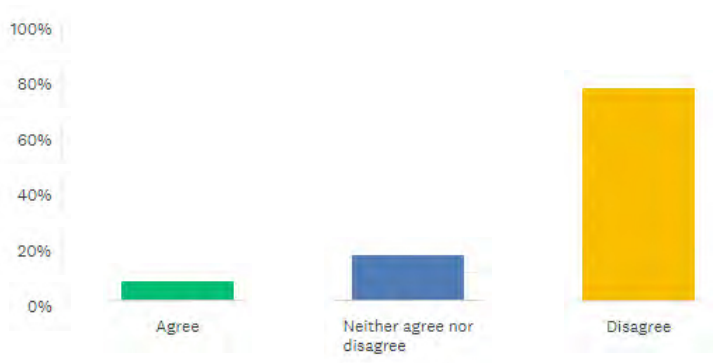

Nearly all of the respondents were aware of news regarding vaping-related illnesses (89.15\%, $\mathrm{N}=115)$, and government policies and bills regarding bans and stricter regulations for e-cigarettes $(83.72 \%, \mathrm{~N}=108)$.

\section{Inferential Statistics}

Inferential statistics were conducted using NCSS statistical software. This study has set the significance level at $95 \%$ where $\mathrm{p}=0.05$. Chi-square tests involving age had two categories combined due to a lack of respondents - those ages 46-55 and 55+. Thirteen Chi-Square tests were conducted.

\section{Chi Square Results}

Age had no statistically significant association to a person's support of increased vaping regulations $(\mathrm{P}=0.49141)$ or the perception that e-cigarettes are equally as harmful to tobacco cigarettes $(\mathrm{P}=0.15802)$. However, results involving age are limited due to a small sample size of participants over 45 years old $(\mathrm{n}<30)$.

Six associations were found comparing a person's smoking/vaping status to the participant's:
- $\quad$ support of stricter e-cigarette regulations or bans relative to tobacco $(\mathrm{P}=0.0065)$

- perception that e-cigarettes are as harmful as tobacco $(\mathrm{P}=0.00002)$

- belief in e-cigarettes use as an effective smoking cessation tool $(\mathrm{P}=0.00007)$

- belief that e-cigarettes can improve a person's health $(\mathrm{P}=0.00000)$

- perception that e-cigarettes are okay to use around non-smokers $(\mathrm{P}=0.0000)$

- perception that e-cigarettes are okay to use around children $(\mathrm{P}=0.0010)$

No associations were found comparing a person's smoking/vaping status to the perception that vaping is harmless $(\mathrm{P}=0.21087)$.

Out of four chi-square tests involving media exposure, one association was found between participant exposure of government actions towards e-cigarettes and perception of e-cigarettes being as harmful as tobacco cigarettes $(\mathrm{P}=0.01395)$. However, tests involving awareness of e-cigarette related media are limited due to small sample sizes of participants unaware of such media $(\mathrm{n}<30)$.

\section{Discussion}

Tests involving age were conducted as it is known that high school and youth vaping rates are increasing, therefore 
there is likely to be an association between age and harm perceptions of ecigarettes (Shiplo, Czoli, \& Hammond, 2015).

Results show that e-cigarette users and tobacco users generally view e-cigarettes and vaping more favourably compared to non users. However, despite general favourability, a significant percentage of tobacco users still had unfavorable views of e-cigarettes in terms of harm perceptions. One example is shown below in Table 2 where nine tobacco users agreed that e-cigarettes were just as harmful compared to tobacco.

TABLE 1. CONTINGENCY TABLE OF SMOKING/VAPING STATUS TO PERCEPTION OF E-CIGARETTES BEING AS HARMFUL AS TOBACCO
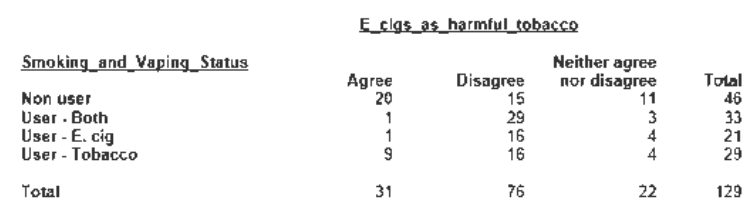

This is in contrast with Public Health England's assertion that e-cigarettes are 95\% safer compared to traditional ecigarettes and supports their finding that the general perception of e-cigarettes is trending negatively (Mcneill et al., 2015). Evidence shows that tobacco users can gain the most health benefits from ecigarette use as there are fewer toxic chemicals found in e-cigarettes due to the lack of combustion (Farsalinos \& Polosa, 2014; Hajek et al., 2019; Hammond, 2019; Mcneill et al., 2015).

There is a disparity between the perceptions of e-cigarette safety and its effectiveness as a smoking cessation tool. The results show a significant number of tobacco users $(\mathrm{N}=6,20.6 \%)$ disagree that it is effective for smoking cessation. In addition, the majority of tobacco users disagree $(\mathrm{N}=16,57.1 \%)$ that it can improve their health signifying that there is misinformation about accurate health effects regarding the effects of vaping, meaning that e-cigarettes as a smoking cessation tool can be better communicated to smokers.

A significant portion of dual-users agreed that it was okay to use e-cigarettes around non-smokers. Dual-users were also more likely to agree that it was okay to use these products around children. It may be possible that these users are underestimating the effects of vaping and second-hand smoke effects. Second-hand smoke has been found to negatively impact indoor air quality, releasing emissions containing particulate matter, volatile organic compounds, polyaromatic hydrocarbons, carbonyls, and heavy metals (Schrober et al., 2014). Although the doses may be minimal, e-cigarettes do contain emissions that are known to be harmful to human health and exposure should be kept to a minimum.

Almost all participants disagreed that ecigarettes were harmless which shows awareness that it can cause health issues. Non-users disagreed $(\mathrm{N}=45,96 \%)$ that ecigarettes could benefit their health, which is correct as studies show ecigarettes still contains chemicals which 
are not beneficial and can cause harm (CDC, 2020; Hammond et al., 2019). There is also the potential for it to act as a gateway drug leading into other substances (i.e. tobacco) (Hammond et al., 2019).

This study could not determine if media had an association with this misinformation due to inadequate sample sizes for participants unaware of news relating to vaping related illnesses or government discussions regarding bans. Most participants were also not in favour of regulations or bans that go beyond tobacco regulations. Attempts at banning e-cigarettes may be met with public backlash and outrage.

An associations was found between exposure to news regarding stricter regulations/bans and the perception of ecigarettes being as harmful as tobacco cigarettes. The association between negative news/media and vaping perception was weaker than anticipated, especially compared to the findings from Public Health England (Mcneill et al., 2015). At the time of this research the outbreak of vaping related illnesses was novel and news was widespread, so a greater association was anticipated. The lack of associations may be due to a small sample size from participants who were unaware of such news.

\section{Knowledge Translation}

In general, participants acknowledge that e-cigarettes are not completely harmless and this can be a starting point in education initiatives to discourage new non-smokers from engaging with ecigarettes. The greatest concern involves youth vaping and currently programs educating youths in high schools and middle school are implemented in the form of tours, videos, advertisements and pamphlets (Health Canada, 2019). There are also continuing regulatory changes to vaping in British Columbia including health label warnings, higher taxes, limits on nicotine content, and constraints on packaging (Lindsay, 2019). The drawback is that these approaches makes e-cigarettes look dangerous and unappealing as a cessation option for smokers.

Health professionals were found to be unlikely to recommend vaping as a smoking cessation method as many of them believe them to be harmful and addictive (Shin et al., 2017; Zgliczyński et al., 2019). Education targeting health professionals would help alleviate misinformation and allow accurate assessments for patients seeking to quit tobacco. This method would allow tobacco users to receive accurate information regarding vaping while hiding information that might entice nonusers to start using e-cigarettes. Understandably there may be liabilities when recommending vaping products to patients, but the health professional can still provide information regarding the effects of vaping in an objective manner 
leaving the final choice to the patient. For this to be effective, health professionals must be aware of actual benefits and risks to vaping.

\section{Limitations}

Finding adequate sample sizes for certain groups posed a challenge. Namely finding tobacco smokers, older populations, and people unaware of vaping related news posed a challenge. Online groups consisting of tobacco users are generally enthusiasts who do so out of enjoyment rather than addiction and would not be representative of the general public (i.e. pipe tobacco, cigars). Older populations tend to not use the internet as much as younger populations and specialized sites are difficult to obtain permission to post surveys and to find. Due to the outbreaks of vaping related illnesses in the past year (August 2019- March 2020), most people are aware of vaping related news and thus can't be compared to unaware groups. This comparison could be done to prior research and is a potential topic for future research. Improvements on outreach to specific groups (older populations, tobacco users) can also be improved on for future research.

In hindsight, several questions could have been improved on and included. For example, the questions involving vaping around children or non-users may be vague as it can implicate health problems or the fact that it normalizes vaping as a behaviour. More meaning could be derived by asking about the harms of second-hand vapours instead. Vaping is also a hotly debated topic and many participants sent feedback saying that the survey was too restrictive in the answers. An open ended question for comments should be available at the end of the survey for participants to provide insight that may be overlooked.

\section{Future Research}

Concerns and studies about e-cigarettes are continuously evolving and changing. Future research can build on this study by:

1. Composing another survey with updated questions and specific ways to target tobacco users and older populations to build on this research.

2. Determining what misconceptions exist through a knowledge tests and identify effective ways for education dissemination. An example of a question is: do all e-cigarettes contain nicotine?

\section{Analyze different vaping flavoured} products to identify and quantify respiratory irritants from vapour emissions and compare them to air quality guidelines.

\section{Survey health professionals to assess current knowledge levels regarding vaping}

\section{Conclusion}

A significant number of respondents answered in ways that signify a 
misunderstanding of e-cigarette health effects. Non-users and a percentage of tobacco users seem to overstate the health consequences and tobacco smokers who transitioned are understating the health effects. Youth vaping rates are currently escalating and one factor attributable to this rise is a misunderstanding of health consequences and addictive properties of vaping. It is also possible that tobacco users are developing negative perceptions of vaping and will be less likely to switch. Extreme legislative action to ban or restrict e-cigarettes could incite outrage and receive negative press. Education that deters non-users from vaping while encouraging tobacco users to quit by presenting accurate information is ideal.

\section{Competing Interests}

The authors declare they have no competing interests

\section{References}

BBC News. (2019). India e-cigarettes: Ban announced to prevent youth "epidemic."

BCIT. (2020). Research Ethics. Retrieved from https://www.bcit.ca/appliedresearch/ ethics/

Behar, R. Z., Davis, B., Wang, Y., Bahl, V., Lin, S., \& Talbot, P. (2014). Identification of toxicants in cinnamon-flavored electronic cigarette refill fluids. Toxicology in Vitro, 28(2), 198-208. https://doi.org/10.1016/j.tiv.2013.10. 006
Canada Vaping Info. (2019). How much e-liquid will I need? Retrieved from https://canadavapes.com/info/muche-liquid-will-need.html

CBC News. (2019, August 27). Advertising restrictions needed to curb vaping among youth, researchers say. CBC News. Retrieved from https://www.cbc.ca/news/health/ecigarette-advertising-1.5260652

CDC. (2020). Outbreak of Lung Injury Associated with the Use of ECigarette, or Vaping, Products. Retrieved from https://www.cdc.gov/tobacco/basic_i nformation/e-cigarettes/severe-lungdisease.html

Cheng, J. (2020). The Perceived Health Effects of E-cigarette Use Among Adult Smokers. BCIT Environmental Health Journal.

Farsalinos, K. E., \& Polosa, R. (2014). Safety evaluation and risk assessment of electronic cigarettes as tobacco cigarette substitutes: A systematic review. Therapeutic Advances in Drug Safety, 5(2), 6786.

https://doi.org/10.1177/2042098614 524430

FDA. (2019). The Real Cost Campaign. Retrieved from https://www.fda.gov/tobaccoproducts/public-healtheducation/real-cost-campaign

Government of Canada. Vaping Products Labelling and Packaging Regulations, (2020). 
Hajek, P., Phillips-Waller, A., Przulj, D., Pesola, F., Smith, K. M., Bisal, N., ... McRobbie, H. J. (2019). A randomized trial of E-cigarettes versus nicotine-replacement therapy. New England Journal of Medicine, 380(7), 629-637.

https://doi.org/10.1056/NEJMoa180 8779

Hammond, D., Reid, J. L., Rynard, V. L., Fong, G. T., Cummings, K. M., McNeill, A., ... White, C. M. (2019). Prevalence of vaping and smoking among adolescents in Canada, England, and the United States: Repeat national cross sectional surveys. BMJ (Online), 365(May 2018). https://doi.org/10.1136/bmj.12219

Health Canada. (2016). Risks of Smoking. Retrieved March 10, 2019 , from http://healthycanadians.gc.ca/healthy -living-vie-saine/tobaccotabac/risks-risques-eng.php

Health Canada. (2019). Backgrounder: Youth Vaping Prevention Public Education. Retrieved April 4, 2020, from

https://www.canada.ca/en/healthcanada/news/2019/12/backgrounderyouth-vaping-prevention-publiceducation.html

Lindsay, B. (2019). Sweeping new B.C. regulations on vape products include higher taxes, health warnings on packaging. Retrieved April 4, 2020, from

https://www.cbc.ca/news/canada/brit ish-columbia/b-c-new-vapingpolicy-announcement-1.5359457
Mcneill, A., Brose, L., Calder, R., Hitchman, S., Hajek, P., \& McRobbie, H. (2015). E-cigarettes : an evidence update. Public Health England, 111.

Munroe, S. (2019). Legal Canadian Smoking Age by Province and Territory. Retrieved from https://www.thoughtco.com/legalsmoking-age-in-canada-510011

Reid, J., Hammond, D., Tariq, U., Burkhalter, R., Rynard, V., \& Douglas, O. (2019). Tobacco Use in Canada : Patterns and Trends, 2019 Edition. In Tobacco Use in Canada: Patterns and Trends,. Retrieved from http://www.tobaccoreport.ca/2013/T obaccoUseinCanada_2013.pdf

Reuters. (2019). U . S . government announces plans to ban flavoured ecigarettes from market. Retrieved October 3, 2019, from Global News website:

https://globalnews.ca/news/5889257/ us-flavoured-vaping-ban/

Schrober, W., Szendrei, K., Matzen, W., Osiander-Fuchs, H., Heitmann, D., Schettgen, T., ... Fromme, $\mathrm{H}$. (2014). Use of electronic cigarettes (e-cigarettes) impairs indoor air quality and increases FeNO levels of e-cigarette consumers. International Journal of Hygiene and Environmental Health, 217(6), 628637. Retrieved from http://www.sciencedirect.com/scienc e/article/pii/S1438463913001533

Shin, D. W., Kim, Y. Il, Kim, S. J., Kim, J. S., Chong, S. M., Park, Y. S., ... Cho, M. J. (2017). Lung cancer 
specialist physicians' attitudes

towards e-cigarettes: A nationwide

survey. PLoS ONE, 12(2), 1-12.

https://doi.org/10.1371/journal.pone.

0172568

Shiplo, S., Czoli, C. D., \& Hammond, D.

(2015). E-cigarette use in Canada:

Prevalence and patterns of use in a

regulated market. BMJ Open, 5(8),

$1-7$.

https://doi.org/10.1136/bmjopen-

2015-007971

Surveymonkey. (2020). IP Tracking.

Retrieved from

https://help.surveymonkey.com/artic les/en_US/kb/How-do-I-turn-offthe-IP-addresses-collection-on-theresponses

Wang, W., He, Z., Feng, N., \& Cai, Y. (2019). Electronic cigarette use in China: Awareness, prevalence and regulation. Tobacco Induced Diseases, 17(April), 1-11. https://doi.org/10.18332/tid/105393

Wang, X., Zhang, X., Xu, X., \& Gao, Y. (2019). Perceptions and use of electronic cigarettes among young adults in China. Tobacco Induced Diseases, 17(March), 1-14. https://doi.org/10.18332/tid/102788

Zgliczyński, W. S., Jankowski, M., Rostkowska, O., Gujski, M., Wierzba, W., \& Pinkas, J. (2019). Knowledge and Beliefs of ECigarettes Among Physicians in Poland. Medical Science Monitor, 25, 6322-6330.

https://doi.org/10.12659/msm.91692

0 